\title{
Familial nasal acilia syndrome
}

\author{
R Soferman, Z Ne'man, M Livne, A Avital, Z Spirer
}

\begin{abstract}
Mucociliary dysfunction can be caused by the absence of cilia or by abnormalities in their ultrastructure. A family in which some members were suffering from respiratory morbidity due to lack of cilia is described.

(Arch Dis Child 1996;75:76-77)
\end{abstract}

Keywords: nasal cilia.

The familial nasal acilia syndrome is very rare. ${ }^{1}$ We describe four children from one family in which the lack of cilia caused respiratory morbidity.

\section{Hospital, Sourask \\ Medical Center, \\ Tel-Aviv \\ R Soferman \\ Z Spirer}

Department of Pathology, Hadassah Mount Scopus,

Jerusalem

Z Ne'man

Pediatric Allergy and Pulmonology Clinic, Assaf Harofeh Medical

Center

M Livne

Institute of

Pulmonology, Kiryat

Hadassah, Hebrew

University, Jerusalem,

Israel

A Avital

Correspondence to:

Dr R Soferman

Pediatric-Pulmonology

Clinic, Dana Children's

Hospital,

Sourasky Medical Center,

Tel-Aviv, 64239, Israel.

Accepted 8 February 1996



Figure 2 Family pedigree. uneventful pregnancy of 39 weeks. She had respiratory distress at 48 hours, and a chest radiograph revealed an atelectasis of the right upper lobe. The oxygen saturation was $84 \%$, oxygen tension $6.65 \mathrm{kPa}$, carbon dioxide tension $6.00 \mathrm{kPa}$, and $\mathrm{pH} 7.39$. She was treated with $40 \%$ oxygen for 24 hours, with antibiotics (ampicillin and gentamycin), and postural drainage. There was a gradual improvement and at the time of discharge from the newborn department, at the age of 12 days, there were no pathological findings in the chest radiograph. At the age of 17 days she was hospitalised because of dyspnoea, and physical examination disclosed retractions of the intercostal spaces and diffuse rhonchi and rales throughout the lungs. No abnormality was detected on the chest radiograph. Her condition improved spontaneously and she was discharged. Three weeks later, she was hospitalised again because of dyspnoea, appearance of cutis marmorata, and high fever. This time the chest radiograph demonstrated infiltration in the right lower lobe. The blood culture was negative, and the white cell count was $15.0 \times 10^{9} / 1$. Both her clinical condition and chest radiograph improved after erythromycin treatment. Repeated sweat tests demonstrated normal chloride concentrations $(30-37 \mathrm{mmol} / \mathrm{l})$, and repeated nasal culture revealed normal flora. No immunoglobulin assay was obtained because of her young age. Her height and weight centiles were $25 \%$ and $5 \%$ respectively. Ultrastructural studies of the respiratory epithelium $^{2}$ were performed on specimens obtained by a double nasal brush biopsy from the inferior turbinate when the patient was clinicaly well. ${ }^{3}$ In each sample a minimum number of 100 epithelial cells were randomly selected and analysed and found not to be ciliated.

The same procedure of nasal brush biopsy was repeated three months later and the same picture of unciliated epithelial cells was demonstrated (fig 1). It is noteworthy that during this period of time she continued to suffer from recurrent upper and lower respiratory tract infections.

The index child's parents were second degree relatives (fig 2). Her sister and two cousins (siblings), suffered from recurrent upper and lower respiratory tract infections including chronic sinusitis. One of them had recurrent episodes of lobar atelectasis and all the three had evidence of lung bronchiectasis. The girl cousin had demonstrated a pathological saccharine test. They were diagnosed at different laboratories as suffering from congenital nasal acilia syndrome. 


\section{Discussion}

The dyskinetic cilia syndrome, which predisposes the respiratory tract to many insults, is considered to be an autosomal recessive inherited disease. ${ }^{4} \mathrm{~A}$ wide spectrum of ciliary defects and concomitant mucociliary dysfunction has been documented. Various congenital and environmental factors have been shown to influence the process of ciliogenesis. ${ }^{5}$ Children who lack cilia are functionally similar to those with dyskinetic cilia syndrome. We believe that the deficiency of nasal cilia in this patient is a primary defect and not a transient denudation of the cilia that may occur after infection or as a result of some other insult, because the first episode of lung atelectasis occurred at the age of 48 hours, and the nasal ciliary brush biopsy specimen was obtained at a period of time when there was no evidence of upper respiratory tract infection.

There are some reported cases of nasal acilia syndrome, ${ }^{67}$ and a description of a family in which the father and all three children appeared to have this syndrome. ${ }^{1}$ This present case report emphasises the importance of the nasal ciliary brush biopsy in evaluating a patient suffering from respiratory morbidity.

We are indebeted to Dr I Catz the manager of the Pediatric Allergy and Pulmonology Clinic, Assaf Harofeh, for his cooperation.

1 Babin RW, Kavanagh KT. Familial nasal acilia syndrome. South Med f 1985; 78: 737-9.

2 Lungarella G, Fonzi L, Ermini G. Abnormalities of bronchial cilia in patients with chronic bronchitis. Lung 1983; 161: 147-56.

3 Rutland J, Cole PJ. Non-invasive sampling of nasal cilia for measurement of beat frequency and study of ultrastructure. Lancet 1980; ii: 564-5.

4 Sturgess JM, Thompson MW, Czegledy-Nagy E, Turner JAP. Genetic aspects of immotile cilia syndrome. $A m \mathcal{F}$ Med Genet 1986; 25: 149-60.

5 Richard S, Neselof C, Pfister A, de Blic J, Scheinmann P, Paupe J. Congenital ciliary aplasia in two siblings. A primitive disregulation of ciliogenesis? Pathol Res Pract 1989; 185: $181-3$

6 Dudley JP, Welch MJ, Stiehm ER, Carney JM, SoderbergWarner M. Scanning and transmission electron microscopic aspects of the nasal acilia syndrome. Laryngoscope 1982; 92: 297-9.

7 Phillips JI. Lack of cilia and squamous metaplasia in upper respiratory tract biopsies from children. S Afr Med 7 1989; 